\title{
Asynchronous food availability on neighboring Caribbean coral reefs determines seasonal patterns of growth and reproduction for the herbivorous parrotfish Scarus iserti
}

\author{
Kenneth E. Clifton* \\ Smithsonian Tropical Research Institute (STRI), Apartada 2072, Balboa, Republic of Panama
}

\begin{abstract}
Little is currently known about the temporal linkage between naturally occurring food levels and patterns of growth, reproduction, and feeding behavior by fishes on coral reefs. This study examines seasonal changes in these variables for populations of the herbivorous striped parrotfish Scarus iserti on 2 reefs in the San Blas region of Panama. Although less than $3 \mathrm{~km}$ apart, these populations experience notably different environmental conditions during Panama's annual cycle of rainfall and drought. In response to lower rainfall and higher dry-season winds and wave action, the renewal rate and standing crop of the striped parrotfish's algal food fell on a semi-exposed reef while rising on a more protected reef. Opposite trends occurred when wind and waves abated with the return of the wet season. In response, parrotfish on the 2 reefs showed opposite patterns of seasonal growth and reproduction, indicating that reef-associated environmental conditions determine seasonal peaks of reproduction for these fish. This result challenges the notion that planktonic conditions encountered during early life-history stages generally drive seasonal reproduction by coral reef fishes.
\end{abstract}

KEY WORDS: Coral reef fish · Scarus · Food availability · Growth · Reproductive seasonality

\section{INTRODUCTION}

Many tropical reef fishes express distinct annual cycles of reproduction and growth (e.g. Johannes 1978, Munro 1983, Thresher 1984, Robertson 1990). Despite their obvious relevance to studies of coral reef ecology and fisheries, these cycles and their origins remain poorly understood. Discussions of potential causal mechanisms focus on the bipartite life history of reef fishes (reviewed by Robertson 1991). If adults experience relatively constant environmental conditions (a common assumption for tropical habitats), seasonal peaks of reproduction or growth may simply reflect annually variable, but predictable, patterns of survival and growth for eggs, larvae, or recently settled juveniles. Alternatively, reproductive seasonality could

\footnotetext{
-Address for correspondence and reprints: STRI (Panama), Unit 0948, APO, AA 34002-0948, USA
}

stem from annually shifting reef-based, environmental factors that affect an adult's ability to reproduce, grow, and/or survive. While these hypotheses represent extreme views (patterns of reproduction should evolve from the suite of factors affecting all stages of life; Stearns 1992), most studies to date conclude that environmental conditions experienced during the early stages of life history typically drive patterns of seasonal reproduction by coral reef fishes (e.g. Russell et al. 1977, Lobel 1978, 1989, Doherty 1983, Bakun 1986, Davis \& West 1993, but see Robertson 1990).

Several lines of evidence challenge the generality of this conclusion. Similar species from the same area, as well as single species from different locations within the same geographic region, can show different seasonal spawning regimes (e.g. Walsh 1987, Milton \& Blaber 1990, Robertson 1991). Consistent latitudinal patterns of interspecific spawning seasonality are also often lacking (Robertson 1991). Finally, several recent 
studies describe correlations between seasonal shifts in the adult environment and temporal patterns of reproduction (Fishelson et al. 1987, McClanahan 1988, Montgomery et al. 1989, Robertson 1990, Rajasilta 1992). Although pelagic conditions might still be driving seasonal peaks of spawning in such cases (i.e. if periods of maximal egg or larval survival coincide with optimal environmental conditions for adult reproduction), these results encourage further study of the 'adult' factors influencing seasonal reproduction of coral reef fishes.

This paper describes seasonal patterns of food availability, growth, and reproduction for 2 populations of Caribbean striped parrotfish Scarus iserti (formerly S. croicensis; Randall \& Nelson 1979). Although separated by less than $3 \mathrm{~km}$, these populations encounter rather different seasonally changing environmental conditions. Given both their initial proximity and the extended planktonic larval stage of the study species ( $24 \mathrm{~d}$; B. C. Victor pers. comm.), it seems highly unlikely that propagules produced from these 2 sites experience drastically different pelagic conditions (striped parrotfish in the study area recruit year-round, with no obvious seasonality; D. R. Robertson pers. comm.). These fish thus provide a unique opportunity to examine how seasonal changes in the reef environment influence temporal patterns of adult growth and reproduction.

\section{METHODS}

Subject animal and location. Scarus iserti is a common inhabitant of Caribbean reefs (Randall 1983, Böhlke \& Chaplin 1992). These small (up to $15 \mathrm{~cm}$, all fish lengths reported as standard length) herbivores spend much of their time scraping films of epilithic microalgae and benthic diatoms from inorganic substrata (Randall 1967). Like other Caribbean scarids, $S$. iserti change sex from female to male and spawn throughout the year (Robertson \& Warner 1978). They spawn during the afternoon, either as pairs or in groups (Colin 1978, Robertson \& Warner 1978). Females and smaller males are of the striped Initial Phase (IP), while larger males are always of the more colorful Terminal Phase (TP). In San Blas, Panama, both sexes mature at $\sim 65 \mathrm{~mm}$ (Warner \& Downs 1977). The social habits and life-history tactics of these gregarious fish are reasonably well known from a variety of studies (Buckman \& Ogden 1973, Ogden \& Buckman 1973, Barlow 1975, Robertson et al. 1976, Warner \& Downs 1977, Colin 1978, Robertson \& Warner 1978, Colin \& Clavijo 1988, Clifton 1989, 1991). I conducted the present study in the vicinity of the Smithsonian Tropical Research Institute's San Blas field station, where much of this previous research was also done.
Panama annually experiences a distinct wet and dry season (Cubit et al. 1989). The wet season in San Blas (May-December) generates light and variable winds, mild currents, and intermittently heavy rain. These rains effectively stop during a dry season (January-April) characterized by consistently strong (15 to 20 knot) northerly winds that produce heavy surf, currents, and turbid water.

Two reefs in the San Blas region (see Robertson 1987 for detailed map) were chosen for their location and their consistently dense $\left(\sim 50\right.$ fish per $\left.100 \mathrm{~m}^{2}\right)$ and dominant (representing more than $91 \%$ numerically of the resident non-territorial herbivorous fishes on both reefs) striped parrotfish populations. Ulagsukun-C (UL-C) is a south-facing fringing reef that lies $\sim 300 \mathrm{~m}$ from the Panamanian mainland. This reef experiences sporadically high levels of discharge from a nearby river during the wet season but is effectively protected from wind and waves during the dry season. Wichibuala 19 (WI-19) is a relatively large $\left(2000 \mathrm{~m}^{2}\right)$ patch reef located $2.7 \mathrm{~km}$ northeast of UL-C. Although semiprotected by a barrier reef to the north, WI-19 is exposed to high wave energy and turbid water during the dry season.

General environmental conditions, including rainfall, solar radiation, wind speed, and wind direction, are recorded continuously at the Smithsonian's San Blas field station, which lies between the 2 study reefs. Water temperatures during the study were measured bimonthly at both reefs with a calibrated thermometer. Salinity, which may affect algal growth (Lobban 1985), was measured at both reefs using a hand-held refractometer (Reichert-Jung T/C meter \# 10419) from water samples collected on at least 5 days, each season, at a depth of 1 to $3 \mathrm{~m}$. Water clarity at both reefs was visually estimated at least once a week throughout the study.

Food resources. I estimated the quantity, quality, renewal, and harvest rate of algal food resources on both reefs from algae growing on unglazed ceramic tiles $\left(5.3 \mathrm{~cm}^{2}\right)$. In September 1991, 3 or 4 sets of 15 tiles each $(3 \times 5$ grid) were placed at 3 sites on each reef where striped parrotfish typically fed. These were left undisturbed for at least $45 \mathrm{~d}$, sufficient time to acquire algal films that do not differ from those found on natural substrate (Clifton 1989). Striped parrotfish feed unselectively on such algae and treat tiles as a natural part of the reef, scraping small (4 to $8 \mathrm{~mm}^{2}$ ) sections of algae from the tile's upper surface with each bite. Algae collected from tiles at different times and places thus provide spatial and temporal estimates of the food resources available to a reef fish. At any one time, different tiles within a grid show relatively little variance in the algal growths they support (Clifton 1991).

Algal standing crop (quantity), total inorganic matter (an estimate of sediment load), and percent organic 
matter (an indirect measure of quality) were estimated monthly between November 1991 and October 1992 from the ash-free analysis of material scraped from the entire upper surface of 3 randomly selected tiles from each site (i.e. a total of 216 tiles resulting from 9 samples from each reef, each month). Scrapings were rinsed briefly in distilled water, and then preserved in $4 \%$ buffered formalin. Individual samples were later dried for at least $24 \mathrm{~h}$ at $60^{\circ} \mathrm{C}$ in a preweighed ceramic crucible, weighed to the nearest $0.1 \mathrm{mg}$, then ashed for $4 \mathrm{~h}$ at $450^{\circ} \mathrm{C}$ before reweighing (samples always cooled to room temperature in a desiccator before weighing). Monthly collections from the 2 reefs were made within $3 \mathrm{~d}$ of one another (usually on consecutive days) at approximately 15:00 h.

Algal food quality on the reefs was also directly estimated from the nitrogen content of algal samples collected (as above) roughly every other month. Following rinsing, the sample was immediately frozen, then later dried. A small homogenized portion $(\sim 10 \mathrm{mg})$ was then analyzed chromatographically for carbon, nitrogen, and hydrogen content at the University of California Marine Science Analytic Laboratory at Santa Barbara (Leeman Labs model $440 \mathrm{CHN}$ elemental analyzer, calibrated both with Acetanilide and a citrus leaf standard run every tenth sample). The remaining portion of the sample was subsequently analyzed for ash-free dry weight.

I experimentally determined the renewal rate and, indirectly, the harvest of algal food on each reef by comparing tiles protected and unprotected from grazing (all tiles were exposed to natural grazing by parrotfish, as above, prior to each experimental trial). For each trial, 3 random tiles from adjacent sets at 1 site on each reef were initially collected between 06:00 and 06:30 h, before striped parrotfish emerged from their sleeping areas. Following this initial collection, 1 randomly selected set of tiles was covered with $1.6 \mathrm{~cm}^{2}$ mesh hardware cloth (to prevent grazing by striped parrotfish or other, less frequent herbivores; each cover sat $\sim 1 \mathrm{~cm}$ above the surface of the tiles). Three additional tiles from both covered and uncovered treatments were subsequently collected between $18: 00$ and $18: 30 \mathrm{~h}$ of the same day on both reefs. This procedure was repeated for the 2 other sites on each reef on the following 2 days. All samples were analyzed for ash-free dry weight.

Growth, reproduction, condition and behavior of striped parrotfish. Over 100 non-territorial female striped parrotfish (ranging in size from 55 to $100 \mathrm{~mm}$ ) from each reef were initially captured in October 1991 with a fine $\left(1 \mathrm{~cm}^{2}\right)$ mesh monofilament wall net. The distribution of these fish within 6 size classes was not different between the 2 reefs $\left(\mathrm{n}_{\mathrm{Wl}-19}=135\right.$, $\mathrm{n}_{\text {UL-C }}=121$; Kolmogorov-Smirnov statistic: $D=0.06, \mathrm{p} \gg$ 0.05 ). These fish were sexed, measured (to $0.1 \mathrm{~mm}$ ), and uniquely tagged with innocuous injections of vital stain Alcian Blue 8GX under their scales (Kelly 1967). To test for tag effects upon growth, 23 individually recognizable fish from UL-C (bearing unique scars or scale patterns) were similarly measured, but not tagged. Individuals in both populations were sampled for growth over the next year by recapturing and measuring tagged fish approximately every other month. At those times, I retagged previously marked fish and tagged new fish within the same size range.

In addition to regular surveys of spawning behavior on both reefs, seasonal reproductive output was estimated from seasonal collections of fish. Just before the end of the 1992 dry and wet seasons, at least 50 untagged females from each reef were captured over a $4 \mathrm{~d}$ period. Fish were collected just after emerging from their sleeping sites to control for gut fullness (Scarus iserti evacuate their guts before sleeping each night and all collected fish had empty guts) and possible differences in diel reproductive schedules on the 2 reefs. Lengths and weights of fish $>65 \mathrm{~mm}$ were noted before gonads and livers were excised, blotted dry, and weighed.

A relationship between gonad size and spawning output was determined by subsequent collections of fish at 13:00 $\mathrm{h}$ (before the daily spawning period of Scarus iserti). Following capture, females were held for at least $2 \mathrm{~h}$ (until eggs were fully hydrated) then the eggs were stripped into $5 \mathrm{ml}$ Pyrex centrifuge tubes containing $\sim 3 \mathrm{ml}$ distilled water. Total egg volume (to $0.05 \mathrm{ml}$ ) was recorded after eggs had settled for 3 to $4 \mathrm{~min}$. Gonad weights were then obtained as above.

Feeding rates of striped parrotfish were determined from numerous $5 \mathrm{~min}$ observations of non-territorial fish at both reefs. Short-duration observations such as these provide good estimates of daily feeding rate (Clifton 1990) and were made at roughly the same time each day (14:00 to $16: 00 \mathrm{~h}$ ) to control for diel feeding rhythms. Data were recorded on an event-recording computer (NEC model 8201A) housed within a bag of heavy-gauge PVC (Ewa-Marine).

\section{RESULTS}

This year-long study encompassed 2 extended periods of wet season and a dry season. As typical for the region (Cubit et al. 1989), rainfall effectively stopped during the last week of December 1991 and resumed the third week of April 1992. Dry-season waters were generally cooler and more saline, however, water clarity increased only at UL-C (Table 1). All values fell well within the range under which tropical marine algae typically thrive (Lobban 1985). 
Table 1. Mean seasonal changes (mean \pm SE) in regional and reef-specific environmental factors off the Caribbean coast of Panama. Wind direction vectors represent the proportional distribution of wind speeds observed at each of 8 compass points over an entire season. For statistical comparisons, results are from ANOVA, where ' $S$ ' is season, ' $R$ ' is reef, and ' $S \times R$ ' is the interaction between season and reef, reported in parentheses below the dependent variable as follows: ${ }^{*} \mathrm{p} \leq 0.05,{ }^{*} \mathrm{p} \leq 0.01, \cdots \mathrm{p} \leq 0.001$

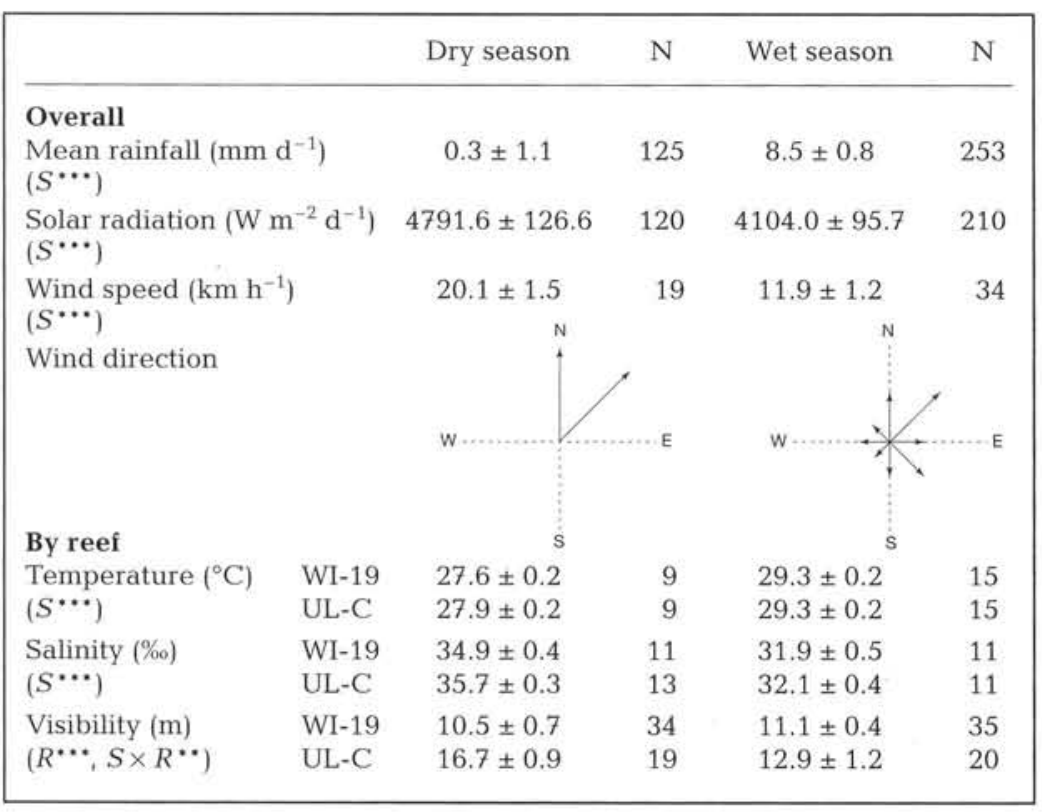

ing faster during dry season, $27.9 \pm 4.2$ $\mathrm{mg} \mathrm{d}^{-1}$ ). Individually recognizable, but untagged, fish grew at similar rates $\left(29.4 \pm 4.9 \mathrm{mg} \mathrm{d}^{-1}, \mathrm{n}=19\right)$ to tagged fish $\left(31.4 \pm 4.2 \mathrm{mg} \mathrm{d}^{-1}, \mathrm{n}=44\right)$ collected at the same time $(t=0.24, \mathrm{df}=61, \mathrm{p}=0.81)$.

Weight gain (accurately estimated from a log-transformed regression between weight and length; $n=243, r^{2}=$ $0.98, \mathrm{p}<0.0001$ ) was chosen for statistical analyses of fish growth (rather than change in length) because weight may more accurately reflect an animal's use of energy for growth (i.e. change in length monitors growth in only 1 dimension). Additionally, unlike change in length, weight gain was found to be unrelated to initial size, simplifying subsequent analyses and data presentation (i.e. after controlling for reef and season effects, smaller fish gained length faster than larger fish while fish of all sizes tended to gain weight at similar rates; ANCOVA for change in size $=$ season + reef + initial size + season $\times$ reef: $F_{1,95}=38.4, \mathrm{p}<$ 0.0001 for change in length; $F_{1,95}=0.7$, $\mathrm{p}=0.39$ for weight gain).

\section{Food resources}

Several notable changes in algal food resources accompanied these seasonal shifts in the physical environment, with algal standing crops (Fig. 1) and algal renewal rates (Table 2 ) on the 2 reefs both showing inverse patterns of change. Specifically, algae were more abundant and, more importantly, renewed more rapidly on WI-19 during the wet season, while at UL-C the opposite trend occurred. Percent organic material and the density of inorganic material on the 2 reefs showed similar trends while algal nitrogen content did not (Table 2).

\section{Growth, reproduction, condition, and behavior}

Patterns of growth and reproduction by striped parrotfish on both study reefs mirrored changes in algal standing crop and renewal rate (Fig. 2). Fish growth at WI-19 was highest during the wet season, while fish at UL-C grew faster during the dry season (Table 3). Perhaps most convincingly, 15 of 16 individuals recaptured at WI-19 during both wet and dry seasons showed higher growth rates during the wet season (mean pairwise difference $=25.1 \pm 4.9 \mathrm{mg} \mathrm{d}^{-1}$ ) while all 13 analogous fish from UL-C showed the opposite trend (grow-
Although striped parrotfish on both reefs spawned throughout the year, their gonadosomatic indices [GSI: (gonad wt/body $w t) \times 1000$ ] roughly matched seasonal patterns of fish growth. The GSI of fish on WI-19 was higher during the wet season while the GSI of fish on

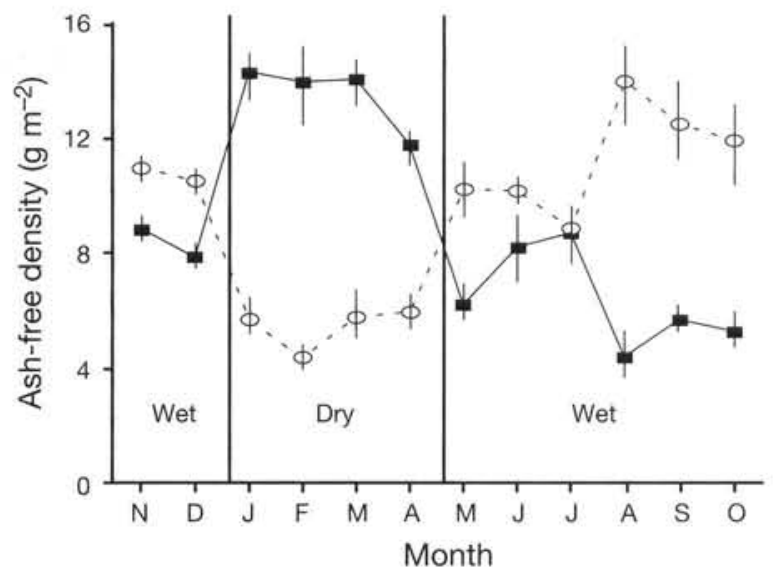

Fig. 1. Monthly mean algal standing crop (density \pm 1 SE) on 2 Caribbean coral reefs between November 1991 and October 1992 ( $N=9$ for each mean; sites within reefs were not different and lumped; nested ANOVA, site within reef: $F_{1,208}=1.5$; $p=0.2$ ). ( $\mathbf{E})$ Algae from the protected reef, UL-C; (O) algae from the exposed reef, WI-19. Vertical lines mark onset of wet and dry seasons 
Table 2. Statistical analysis of algal density, growth, and quality by reef and season (means \pm 1 SE). All weights derived from ashfree analysis. Algal growth rates are means of the mean difference between covered tiles at 06:00 and 18:00 h at each site (sites nested within reef were not different: ANOVA, $F_{4,99}=1.3, \mathrm{p}=0.3$ ). Statistical results reported as in Table 1; ns: not significant

\begin{tabular}{|lcrrr|}
\hline & Reef & Dry season & N & Wet season \\
\hline Algal standing crop $\left(\mathrm{g} \mathrm{m}^{-2}\right)$ & WI-19 & $5.4 \pm 0.4$ & 36 & $11.1 \pm 0.3$ \\
$(R \cdots, S \times R \cdots)$ & UL-C & $13.5 \pm 0.4$ & 36 & 72 \\
Algal growth rate $\left(\mathrm{g} \mathrm{d}^{-1} \mathrm{~m}^{-2}\right)$ & WI-19 & $0.8 \pm 0.6$ & 3 & 72 \\
$(S \cdots, R \cdots, S \times R \cdots)$ & UL-C & $6.6 \pm 0.7$ & $3.8 \pm 0.5$ \\
Inorganic density $\left(\mathrm{g} \mathrm{m}^{-2}\right)$ & WI-19 & $42.6 \pm 3.0$ & $36 \pm 0.3$ \\
$(S \cdot, R \cdots, S \times R \cdot)$ & UL-C & $27.3 \pm 3.0$ & 36 & $32.5 \pm 2.1$ \\
Organic content $(\%$ dry matter) & WI-19 & $12.6 \pm 1.4$ & 36 & $38.0 \pm 2.1$ \\
$(S \cdot, R \cdots, S \times R \cdots)$ & UL-C & $35.6 \pm 1.3$ & 36 & $23.0 \pm 1.0$ \\
Nitrogen content $(\%$ dry plant) & WI-19 & $1.2 \pm 0.2$ & 8 & 72 \\
$($ ns) & UL-C & $1.1 \pm 0.2$ & 8 & 72 \\
\end{tabular}

UL-C was higher during the dry season (Table 3 ). Hepatosomatic indices [LSI: (liver wt/body wt) $\times 1000$ ] showed a strong reef effect (WI-19 > UL-C) and weakly opposite seasonal trend (Table 3). A strong correlation between egg production and gonad weight on both reefs (from stripped fish, $\mathrm{r}^{2}=0.92, \mathrm{n}=188, \mathrm{p}<0.001$ ), with no effect of reef on the regression's slope or intercept (ANCOVA: $F_{1,181}=1.29, \mathrm{p}=0.26$, and $F_{1,81}=2.34$, $p=0.12$, respectively) indicates that relative gonad size provides a good index of spawning output for this species.

Striped parrotfish apparently harvested much of the extra food produced during peaks of algal renewal, even though their feeding rates showed no obvious seasonal changes (Table 3 ). Tiles protected from grazing for $12 \mathrm{~h}$ had significantly greater differences in their standing crop than did algae exposed to natural grazing over the same period (ANOVA, mean differ-

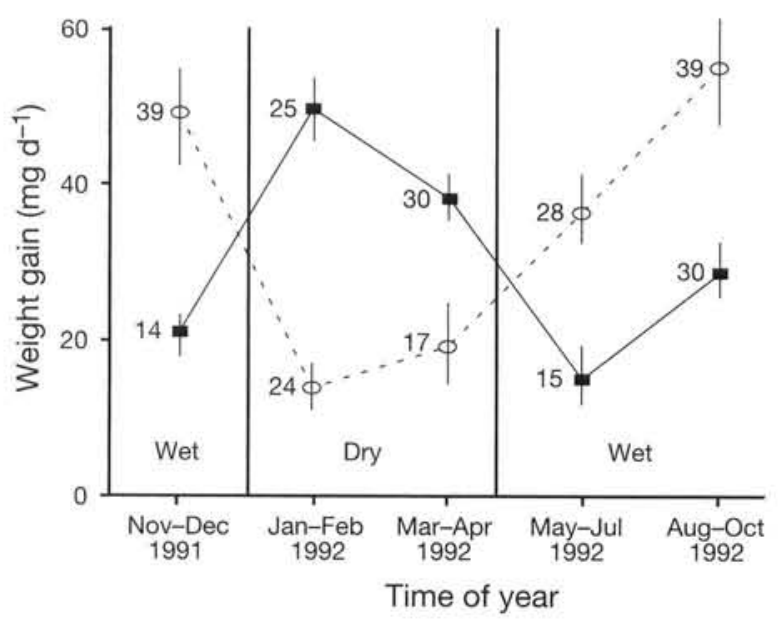

Fig. 2. Scarus iserti. Seasonal changes in mean growth (weight gain $\pm 1 \mathrm{SE}$ ) on 2 Caribbean coral reefs (sample sizes to the left of each mean). Symbols as in Fig. 1 ence between 06:00 and 18:00 $\mathrm{h}$ from each site for covered vs uncovered tiles: $F_{1,31}=56.1, \mathrm{p}<0.0001$, covered vs uncovered tiles were initially the same, ANOVA, tiles from 06:00 h only: $F_{1,99}=0.06, \mathrm{p}=0.81$ ) Thus, when renewal rates were higher, more algae were consumed, since the standing crop of unprotected algae at 18:00 h matched that found at $06: 00 \mathrm{~h}$ (ANOVA, uncovered tiles at $18: 00$ vs $06: 00 \mathrm{~h}: F_{1,99}=$ $0.08, \mathrm{p}=0.78$ ). The notion that striped parrotfish gained additional energy during periods of high algal food availability is further corroborated by correlations between algal renewal rate and several general indices of fish energetic allocation (Fig. 3).

\section{DISCUSSION}

Seasonal climatic changes off the Caribbean coast of Panama clearly altered the availability of food for adult populations of Scarus iserti, and they did so with strikingly localized effects. Algal standing crop and renewal rate increased at a site protected from the dry season's wind-driven surf and currents, while the reverse trend occurred on an exposed reef in the same region. These changes in food availability corresponded directly with similarly contrasting patterns of seasonal growth and reproduction by $S$. iserti on the 2 reefs, implying an important role for the 'adult' environment in determining the seasonal timing of reproduction by these coral reef fish.

Seasonal differences in water clarity, wave exposure, and sedimentation at the 2 study reefs presumably contributed to the observed changes in algal food levels. For example, increased solar radiation and clearer dry-season water probably promoted algal growth at UL-C (also suggested for algae on Kenyan reefs; McClanahan 1988), while more turbid conditions prevented a similar shift at WI-19. Dry season waves and 
Table 3. Scarus iserti. Statistical analysis of seasonal growth, gonad size, liver size, and feeding rates on 2 Caribbean reefs (means $\pm 1 \mathrm{SE}$ ). Statistical results reported as in Table 2

\begin{tabular}{|c|c|c|c|c|c|}
\hline & Reef & Dry season & $\mathrm{N}$ & Wet season & $\mathrm{N}$ \\
\hline Fish growth ( $\left.\mathrm{mg} \mathrm{d}^{-1}\right)$ & WI-19 & $15.1 \pm 6.2$ & 25 & $48.7 \pm 3.11$ & 89 \\
\hline$\left(S^{*}, S \times R \cdots\right)$ & UL-C & $42.2 \pm 5.3$ & 41 & $31.4 \pm 4.2$ & 44 \\
\hline GSI (gonad wt $\times 1000 /$ fish wt) & WI-19 & $11.7 \pm 2.7$ & 23 & $19.8 \pm 1.7$ & 62 \\
\hline$\left(S^{*} R^{*} \cdot\right)$ & UL-C & $18.9 \pm 2.5$ & 26 & $11.5 \pm 1.5$ & 77 \\
\hline LSI (liver wt $\times 1000 /$ fish wt) & WI-19 & $46.9 \pm 2.1$ & 23 & $43.9 \pm 1.3$ & 62 \\
\hline$(R \cdots, S \times R \cdots)$ & UL-C & $22.2 \pm 2.0$ & 26 & $28.7 \pm 1.2$ & 70 \\
\hline Bite rate (bites $/ 5 \mathrm{~min}$ ) & WI-19 & $235.4 \pm 12.7$ & 54 & $264.0 \pm 8.6$ & 58 \\
\hline (ns) & UL-C & $242.1 \pm 13.1$ & 38 & $250.9 \pm 16.3$ & 33 \\
\hline
\end{tabular}

turbulence may have also reduced food levels at the exposed reef by physically destroying or sweeping away ephemeral micro-algae and benthic diatoms that are the bulk of a striped parrotfish's diet. Finally, the inverse relationship between sediment load and algal density at UL-C suggests that river discharge may also locally depress algal food supply.
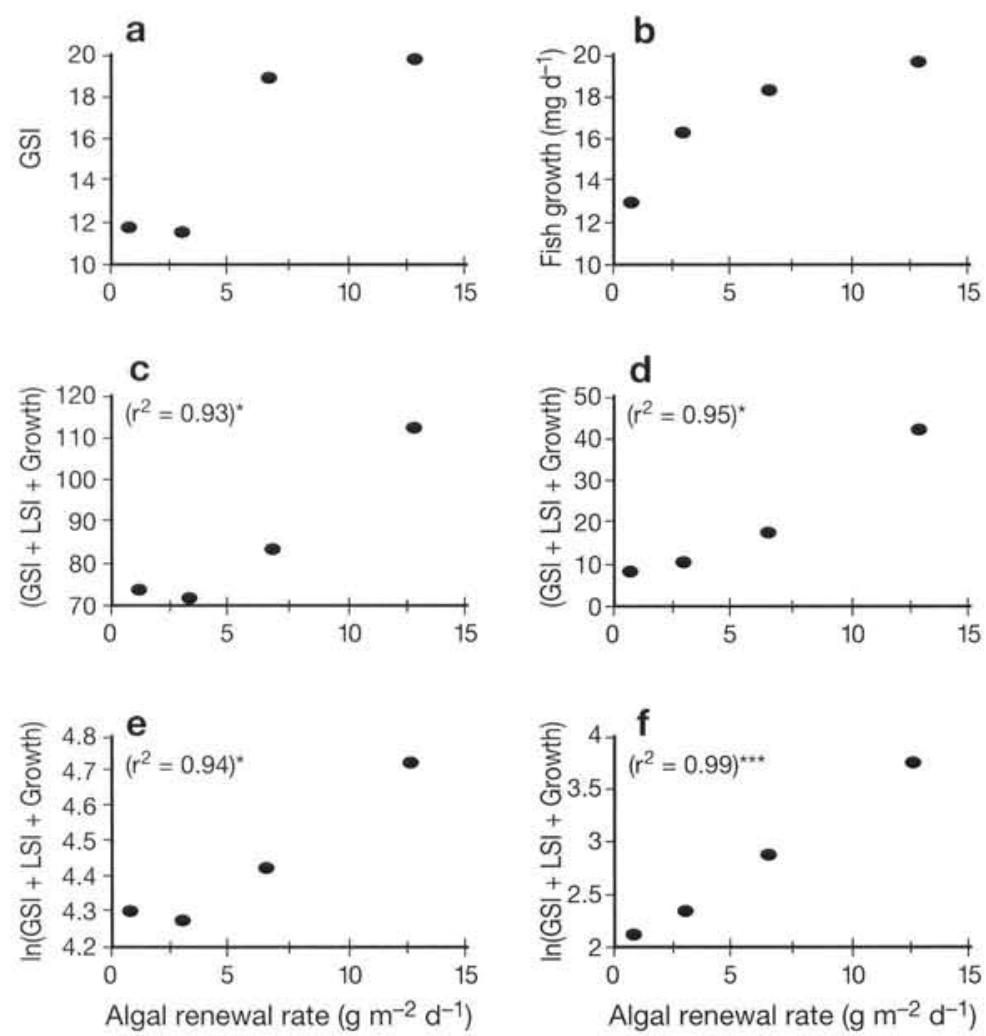

Fig. 3. Scarus iserti. Correlations between algal renewal and the following indices of energetic allocation by striped parrotfish. (a) GSI, (b) fish growth, (c, d) the sum and product of GSI, LSI, and fish growth, respectively, (e, f) the log-transformations of (c) and (d), respectively. Each point represents the mean for a particular reef and season (from low to high algal renewal: WI-19 dry, UL-C wet, UL-C dry, WI-19 wet). Correlation coefficients given when $\mathrm{p}<0.05$, with probabilities noted as in Table 1
Whatever the underlying cause, striped parrotfish ostensibly exploited these seasonal increases in food availability, in part, by growing faster. Although seasonal patterns of growth are known for other coral reef fishes (e.g. Jones 1987, Gladstone \& Westoby 1988), and a correlation between algal food levels and fish growth is not unexpected for herbivores (e.g. Jones 1986, Russ \& St. John 1988, Horn 1989), data linking naturally available food resources to seasonal patterns of adult growth are rare for coral reef fishes. The relationship is easily obscured by seasonal covariance among extrinsic factors, other than food, that may also correlate with fish growth (e.g. water temperature; Gladstone \& Westoby 1988). Such correlations were largely absent during the present study, highlighting the effect of food availability upon fish growth. The lack of seasonal change in the nitrogen content of their algal food (nitrogen typically limits the growth and reproduction of herbivorous fish; Horn 1989, Choat 1991) suggests that striped parrotfish during the present study were limited more by the overall availability of similarly nutritious algae than by algae of higher nutritive quality.

Striped parrotfish on the 2 study reefs also expressed distinct seasonal patterns of reproduction (although simple observations of year-round spawning behavior might initially suggest otherwise; Robertson \& Warner 1978). As with fish growth, changes in gonad size were positively associated with shifting food availability. When coupled with the strong relationship between gonad size and egg production, these changes provide novel evidence for a temporal connection between adult food levels and reproductive output. Although 
by itself such a relationship does not preclude a role for pelagic conditions in the seasonal timing of reproduction (i.e. appropriately lagged seasonal peaks of egg or larval survival in the plankton could coincide with periods of high adult food availability), such a possibility seems remote in the present case, given the prolonged planktonic life of the study species, the proximity of the 2 study populations, and their temporally opposing patterns of reproduction. When taken together, these results virtually ensure that food availability for adult striped parrotfish is the primary determinant of their seasonal reproduction in San Blas.

How pervasive is such a deterministic relationship between seasonal food and reproduction likely to be for coral reef fish? Certainly, it may apply to other regional populations of Scarus iserti, such as those on opposite sides of Jamaica that show seasonally asynchronous patterns of reproduction (with peaks in the early spring on the south side of the island and in the summer to the north, with apparently little or no reproductive activity during other parts of the year; Munro et al. 1973, Colin 1978). Further studies of food availability (on a range of geographic scales) are obviously warranted for this species, as they may provide interesting contrasts between populations (e.g. the more highly seasonal reproduction detected in Jamaica suggests that food levels for adult $S$. iserti may be generally higher in San Blas, where reproductive activity persists year-round). Similar arguments can be made for additional study of scarids off the coast of Kenya that show similar patterns of spatial and temporal reproductive variation (McClanahan 1988).

Seasonal food availability may also explain Robertson's (1990) discovery that several species of damselfish in San Blas have seasonal spawning cycles that appear unrelated to patterns of larval survival. As with striped parrotfish, populations of damselfish on exposed reefs (in the vicinity of WI-19) had lower dryseason spawning levels, suggesting that many herbivores in this part of San Blas are affected by low dry-season levels of algal abundance. It would be interesting to know whether the foods of nonherbivorous fishes in the same area are similarly affected. In general, it seems that a role for adult food should be considered whenever seasonal patterns of reproduction do not obviously relate to planktonic conditions (Robertson 1991).

The idea that larval conditions drive spawning seasonality of tropical reef fish was originally adapted from studies of temperate fish, in which annual cycles of reproduction are obviously linked to patterns of food availability for larvae (Ebling \& Hixon 1991). While it seems likely that some tropical species similarly target optimal moments of growth and survival during early life-history stages (e.g. Doherty 1983, Davis \& West
1993), the data presented here strongly suggest that Scarus iserti in San Blas do not. These different results, derived for different species under different environmental regimes, should not be considered contradictory. Instead, they should encourage further studies of the specific factors that determine whether and to what extent adult as well as larval conditions influence the timing of reproduction by coral reef fishes.

Acknowledgements. I thank A. Bernandez, L. Brey, and especially L. Clifton for their field and laboratory assistance during various stages of this project. Thanks also to $D$. R. Robertson and R. R. Warner for inspiration and comments on preliminary drafts. Finally, I thank the people of Kuna Yala and the Republic of Panama for permission to conduct this study. Smithsonian's Environmental Science Program provided physical data from the San Blas field station. This work was supported by a postdoctoral fellowship from the Smithsonian Tropical Research Institute.

\section{LITERATURE CITED}

Bakun, A. (1986). Local retention of planktonic early life stages in tropical reef/bank demersal systems: the role of vertically-structured hydrodynamic processes. In: Pauly, D., Yanez-Arancibia, A. (eds.) IOC/FAO workshop on recruitment in tropical coastal demersal communities. IOC workshop rep. 44 (suppl.), UNESCO, Paris, p. 15-32

Barlow, G. W. (1975). On the sociobiology of four Puerto Rican parrotfishes (Scaridae). Mar. Biol. 33: 281-293

Böhlke, J. E., Chaplin, C. C. G. (1992). Fishes of the Bahamas and adjacent tropical waters. Livingston Publishing, Pennsylvania

Buckman, N. S., Ogden, J. C. (1973). Territorial behavior of the striped parrotfish, Scarus croicensis, Block (Scaridae). Ecology 54: 1377-1382

Choat, J. H. (1991). The biology of herbivorous fishes on coral reefs. In: Sale, P. F. (ed.) The ecology of fishes on coral reefs. Academic Press, San Diego, p. 120-155

Clifton, K. E. (1989). Territory sharing by the Caribbean striped parrotfish, Scarus iserti: patterns of resource distribution, group size, and behaviour. Anim. Behav. 37: 90-103

Clifton, K. E. (1990). The costs and benefits of territory sharing for the Caribbean coral reef fish, Scarus iserti. Behav. Ecol. Soc. 26: 139-147

Clifton, K. E. (1991). Subordinate group members act as foodfinders within striped parrotfish territories. J. exp. mar. Biol. Ecol. 145: 141-148

Colin, P. L. (1978). Daily and summer-winter variation in mass spawning of the striped parrotfish, Scarus croicensis. Fish Bull. U.S. 76: 117-124

Colin, P. L., Clavijo, I. E. (1988). Spawning activity of fishes producing pelagic eggs on a shelf edge coral reef, southwestern Puerto Rico. Bull. mar. Sci. 43: 249-279

Cubit, J. D., Caffey, H. M., Thompson, R. C., Windsor, D. M. (1989). Meteorology and hydrography of a shoaling reef flat on the Caribbean coast of Panama. Coral Reefs 8: 59-66

Davis, T. L. O., West, G. J. (1993). Maturation, reproductive seasonality, fecundity, and spawning frequency in Lutjanus vittus (Quoy and Gaimard) from the north west shelf of Australia. Fish. Bull. U.S. 91: 224-236 
Doherty, P. J. (1983). Diel, lunar, and seasonal rhythms in the reproduction of 2 tropical damselfishes: Pomacentrus flavicauda and P. wardi. Mar. Biol. 75: 215-224

Ebling, A. W., Hixon, M. A. (1991) Tropical and temperate reef fishes: comparison of community structures In: Sale, P. F. (ed.) The ecology of fishes on coral reefs. Academic Press, San Diego, p. 509-563

Fishelson, L., Montgomery, W. L., Myrberg, A. A. Jr (1987). Biology of surgeonfish Acanthurus nigrofuscus with emphasis on changeover in diet and annual gonadal cycles. Mar. Ecol. Prog. Ser. 39: 37-47

Gladstone, W., Westoby, M. (1988) Growth and reproduction in Canthigaster valentini (Pisces, Tetradontidae): a comparison of a toxic reef fish with other reef fishes. Environ. Biol. Fish 21: 207-221

Horn, M. H. (1989). Biology of marine herbivorous fishes. Oceanogr. mar. Biol. A. Rev. 27: 167-272

Johannes, R. E. (1978). Reproductive strategies of coastal marine fishes in the tropics. Environ. Biol. Fish. 3: 65-84

Jones, G. P. (1986). Food availability affects growth in a coral reef fish. Oecologia 70: 136-139

Jones, G. P. (1987). Competitive interactions among adults and juveniles in a coral reef fish. Ecology 68: 1534-1547

Kelly, W. H. (1967). Marking freshwater and marine fish by injected dyes. Trans. Am. Fish. Soc. 96: 163-175

Lobban, C. S. (1985). The physiological ecology of seaweeds. Cambridge University Press, New York

Lobel, P. S. (1978). Diel, lunar, and seasonal periodicity in the reproductive behavior of the pomacanthid, Centropyge potteri, and some other reef fishes in Hawaii. Pacif. Sci. 32: 193-207

Lobel, P. S. (1989). Ocean current variability and the spawning season of Hawaiian reef fishes. Environ. Biol. Fish. 24: 161-171

McClanahan, T. R. (1988). Seasonality in East Africa's coastal waters. Mar. Ecol. Prog. Ser. 44: 191-199

Milton, D. A., Blaber, S. J. M. (1990). Maturation, spawning seasonality, and proximate spawning stimuli of six species of tuna baitfish in the Solomon Islands. Fish. Bull. U.S. 89: 221-237

Montgomery, W. L., Myrberg, A. A. Jr, Fishelson, L. (1989). Feeding ecology of surgeonfishes (Acanthuridae) in the northern Red Sea, with particular reference to Acanthurus nigrofuscus (Forsskål). J. exp. mar. Biol. Ecol. 132: 179-207

Munro, J. L. (1983). Caribbean coral reef fishery resources. ICLARM Stud. Rev. 7: 1-276

Munro, J. L., Gaut, V. C., Thompson, R., Reeson, P. H. (1973). The spawning seasons of Caribbean reef fishes. J. Fish.

This article was submitted to the editor
Biol. 5: 69-84

Ogden, J. C., Buckman, N. S. (1973). Movements, foraging groups, and diurnal migrations of the striped parrotfish, Scarus croicensis, Block (Scaridae). Ecology 54: 589-596

Rajasilta, M. (1992). Relationship between food, fat, sexual maturation, and spawning time of Baltic herring (Clupea harengus memba) in the Archipelago Sea. Can. J. Fish. Aquat. Sci. 49: 644-654

Randall, J. E. (1967). Food habits of reef fishes of the West Indies. Stud. trop. Oceanogr. 5: 665-847

Randall, J. E. (1983). Caribbean reef fishes, 2nd edn. T. F. H. Publications, Hong Kong

Randall, J. E., Nelson, G. N. (1979). Scarus japanensis, S. quoyi and $S$, iserti: valid names for parrotfishes presently known as $S$. capistatoides, $S$. blochii and $S$. croicensis. Copeia 1979(2): 206-212

Robertson, D. R. (1987). Responses of 2 coral reef toadfishes (Batrachoididae) to the demise of their primary prey, the sea urchin Diadema antillarum. Copeia 1987: 637-642

Robertson, D. R. (1990). Differences in the seasonalities of spawning and recruitment of some small neotropical reef fishes. J. exp. mar. Biol. Ecol. 144: 49-62

Robertson, D. R. (1991). The role of adult biology in the timing of spawning of tropical reef fishes. In: Sale, P. F. (ed.) The ecology of fishes on coral reefs. Academic Press, San Diego, p. 356-386

Robertson, D. R., Sweatman, H. P. A., Fletcher, E. A., Clelland, M. G. (1976). Schooling as a mechanism for circumventing the territoriality of competitors. Ecology 57: 1208-1220

Robertson, D. R., Warner, R. R. (1978). Sexual patterns in the labroid fishes of the western Caribbean. II: the parrotfishes (Scaridae). Smithson. Contrib. Zool. 255: 1-26

Russ, G. R., St John, J. (1988). Diets, growth rates and secondary production of herbivorous coral reef fishes. Proc. Sixth int. Coral Reef Congr. 2: 37-43

Russell, B. C., Anderson, G. R. V., Talbot, F. H. (1977) Seasonality and recruitment of coral reef fishes. Aust. J. mar. freshwat. Res. 28: 521-528

Stearns, S. C. (1992). The evolution of life histories. Oxford University Press, Oxford

Thresher, R. E. (1984). Reproduction in reef fishes. TFH Publ,, Neptune City, NJ

Walsh, W. J. (1987). Patterns of spawning and recruitment in Hawaiian reef fishes. Environ. Biol. Fish. 18: 257-276

Warner, R. R., Downs, I. F. (1977). Comparative life histories: growth vs. reproduction in normal males and sexchanging hermaphrodites in the striped parrotfish Scarus croicensis. Proc. 3rd int. Symp. Coral Reefs Biol. 1: 275-282

Manuscript first received: May 30, 1994

Revised version accepted: September 30, 1994 